\title{
BMJ Open Impact of COVID-19 on patient health and self-care practices: a mixed-methods survey with German patients
}

\author{
Amelia Fiske (D) , ${ }^{1}$ Antonius Schneider, ${ }^{2}$ Stuart McLennan (D) , ${ }^{1}$ \\ Siranush Karapetyan, ${ }^{2}$ Alena Buyx ${ }^{1}$
}

To cite: Fiske A, Schneider A, McLennan S, et al. Impact of COVID-19 on patient health and self-care practices: a mixed-methods survey with German patients. BMJ Open 2021;11:e051167. doi:10.1136/ bmjopen-2021-051167

- Prepublication history and additional supplemental material for this paper are available online. To view these files, please visit the journal online (http://dx.doi.org/10.1136/ bmjopen-2021-051167).

Received 13 March 2021 Accepted 26 August 2021

\section{Check for updates}

(c) Author(s) (or their employer(s)) 2021. Re-use permitted under CC BY-NC. No commercial re-use. See rights and permissions. Published by BMJ.

${ }^{1}$ Institute of History and Ethics in Medicine, TUM School of Medicine, Technical University of Munich, Munich, Germany ${ }^{2}$ Institute of General Practice and Health Services Research, TUM School of Medicine, Technical University of Munich, Munich, Germany

Correspondence to

Dr Amelia Fiske; a.fiske@tum.de

\section{ABSTRACT}

Objective This study aimed to examine German patients': (1) self-estimation of the impact of the pandemic on their health and healthcare; and (2) use of digital self-care practices during the pandemic.

Design Cross-sectional mixed-methods survey. Setting and participants General practice patients from four physicians' offices located in urban and rural areas of Bavaria, Germany, between 21 July 2020 and 17 October 2020. A total of 254 patients participated (55\% response rate); $57 \%$ (262 of 459 ) identified as female and participants had an average age of 39.3 years. Patients were eligible to participate if they were 18 years or older and spoke German, and had access to the internet.

Results (1) Healthcare for patients was affected by the pandemic, and the mental health of a small group of respondents was particularly affected. The risk of depression and anxiety disorder was significantly increased in patients with quarantine experience. (2) Self-care practices have increased; more than one-third $(39 \%)$ of participants indicated that they started a new or additional self-care practice during the pandemic, and about a quarter $(23 \%)$ of patients who were not previously engaged in self-care practices started new self-care activities for the first time; however, such practices were not necessarily digital.

Conclusions Further investigation is required to understand the relationship between digital self-care and public health events such as the COVID-19 pandemic, and to develop strategies to alleviate the burden of the quarantine experience for patients.

\section{INTRODUCTION}

The COVID-19 pandemic has put enormous strain on healthcare systems and has upended the provision of healthcare. Even for those who were not directly affected by the virus itself, the provision of healthcare services was substantially altered. ${ }^{1}$ Concerns have emerged that the postponement of treatment for non-COVID-19 conditions, such as cancer, heart attacks, or stroke, could have significant negative consequences. ${ }^{2}$ Furthermore, with mounting uncertainty, physical and social distancing, job loss and decreased access to support services, the pandemic has increased

\section{Strengths and limitations of this study}

The mixed-methods approach, including validated scales for depression and anxiety, and open-ended qualitative answers on well-being and new health promotion practices, enabled breadth and depth of insight of the study.

- Results are limited to the period after the 'first wave' of the pandemic in Germany and prior to the second lockdown and thus may underestimate the psychological constraints experienced during the second long-term lockdown period.

- Patient involvement in study design and data interpretation was not feasible.

established risk factors for mental health problems. ${ }^{3}$ Recent studies suggest rising rates of depression, anxiety, and stress symptoms during the pandemic. ${ }^{4-11}$

These 'secondary' effects of the pandemic on physical and mental health constitute a significant challenge and require novel approaches given the ongoing course of the pandemic. ${ }^{712}$ One prominent approach that has emerged to assist patients-in lieu of routine healthcare or other ways of maintaining health that are not available during the pandemic-is digital self-care. ${ }^{13-17}$ Selfcare, defined by the WHO as 'the activities that individuals, families, and communities undertake with the intention of enhancing health, preventing disease, limiting illness, and restoring health', ${ }^{18}$ has taken on new forms in the digital era. The growth of the internet and personalised portable devices, such as smartphones, activity trackers, and other digital applications has given rise to emerging forms of digital self-care, a range of practices of maintaining and promoting health without formal medical direction that largely became possible through the datafication and digitisation of patients' bodies and lives. ${ }^{13}$ Many of these practices entail measurements or technologies that were previously only available 
under clinical supervision, which have now moved into the hands of patients. Proponents have predicted that digital self-care represents a novel, cost-effective, and empowering way of addressing the mental and physical health needs of patients. ${ }^{16}$ Indeed, the current pandemic has given rise to a range of digital self-care tools that can be used at home, ${ }^{19-21}$ and has renewed interest in existing digital tools, such as therapeutic chatbots. ${ }^{22}$ It remains unclear, however, if patients are engaging in digital selfcare practices to address health needs brought about by the pandemic.

Germany, and the state of Bavaria in particular, provides a useful setting to examine these issues. The first confirmed COVID-19 case in Germany occurred in Bavaria in late January $2020 .^{23}$ Soon after, Germany began to introduce public health measures to slow the spread and contain the pandemic. ${ }^{24}$ During March and April 2020, measures began affecting the German health system; dentists' and doctors' offices closed or changed their services, hospitals received orders from the federal government in March 2020 to postpone non-essential operations, ${ }^{25} 26$ and intensive care capacities in hospitals were expanded. During spring 2020, Bavaria was also under a 'strict lockdown' in this period, with a stay-at-home order in place, and nonessential shops and businesses along with schools and daycare centres were closed. ${ }^{27}$ Furthermore, Germany is one of the world's first countries to approve digital health apps for prescription as part of a new law on digital medical care. ${ }^{28}$ It is therefore expected that such digital health tools will be increasingly used by German patients. Research conducted before the pandemic indicates that patient-driven digital self-care is currently lagging behind expectations. ${ }^{13}$ Nevertheless, a number of COVID-19 digital tools for patients have emerged in Germany, such as symptom trackers (eg, Data4Life app) and self-help apps for depression. ${ }^{29}$ This study therefore aimed to examine German patients': (1) self-estimation of the impact of the pandemic on their health and healthcare; and (2) use of digital self-care practices during the pandemic.

\section{METHODS}

The methods of the study are presented in accordance with the 'Strengthening the Reporting of Observational Studies in Epidemiology' statement and the 'Standards for Reporting Qualitative Research' ${ }^{30} 31$ The full length survey is available in the online supplemental appendices 1 and 2.

\section{Survey implementation}

A cross-sectional survey was conducted between 21 July 2020 and 17 October 2020. Patients from four general practices in the urban and rural areas of Bavaria were consecutively invited by the practice assistants to participate. Patients were eligible to participate if they were 18 years or older, spoke German, and had access to the internet. Office assistants asked eligible patients who visited in the office during the recruitment period for an appointment if they would like to participate in the study. A total of 459 individuals were provided with the study information sheet in print form, which included a link to the online survey. Office assistants received a small monetary compensation for their help. The online survey was conducted using the automation software EvaSys (EvaSys Central Evaluation V.8.0). Data were then exported into SPSS V.26 for Windows (IBM Corporation). Participants who completed the survey were eligible to claim a $€ 10$ gift certificate for Amazon.

\section{Survey content}

In order to assess the overall well-being of the participants during the pandemic, two subscales of the German version of the Patient Health Questionnaire (PHQ-D) were used to assess depression and anxiety as psychological comorbidity. ${ }^{32}$ The depression severity score of the PHQ, the PHQ-9, ranges from 0 (no depression) to 27 (maximal depression). Superior validity of the PHQ compared with other established self-report questionnaires has been confirmed with respect to the diagnoses of 'major depressive disorder' and 'other depressive disorders' according to the International Classification of Diseases (ICD-10). ${ }^{20}$ Another module of the PHQ-D, the Generalized Anxiety Disorder Scale (GAD-7), was used as a practical self-report anxiety questionnaire that has been validated in primary care. ${ }^{33}$ GAD-7 scores range from 0 to 21 , with scores of $\geq 5,>10$, and $\geq 15$ representing mild, moderate, and severe anxiety symptom levels, respectively. Only moderate and severe scoring were rated as anxiety disorder.

Additionally, a questionnaire was developed to examine the impact of the pandemic on patients' lives and health, and new digital self-care practices. The survey was informed by existing literature on the secondary effects of the pandemic and changing practices of digital selfcare, ${ }^{13} 1734-36$ and combined scaled or yes/no questions, with free-text responses. Demographic questions asked for the participants' age and gender. Two questions asked in the survey were removed due to inconsistent answering patterns.

\section{Data analysis}

Baseline data were analysed descriptively. For the analyses, we included all participants who answered the respective question. Associations between the questions regarding the self-estimation of the healthcare situation and depression or anxiety disorder were investigated separately with multivariable logistic regression models. Survey questions were included into the models as predictor variables. We controlled for potential confounding by including age and gender into the models. Hypotheses testing was performed with an exploratory two-sided test using a significance level of 5\%. All analyses were performed by SK and AS in SPSS V.26 and R V.4.0.3 (The R Foundation for Statistical Computing). Qualitative data from the open responses were analysed by $\mathrm{AF}$ using conventional content analysis, with a focus on conceptual analysis. Initial topics emerging from the responses were identified 
using a process of open coding, codes were generated and grouped based on higher order categories. ${ }^{37}$ Two other investigators $(\mathrm{AB}, \mathrm{SM})$ reviewed the initial analysis to ensure consistency and validity, and conversations among the investigators continued until consensus was achieved. Variance and saturation within the responses was analysed and described. Quotes included in this article were translated from German to English.

\section{Patient and public involvement}

No patient was involved in the design of this study.

\section{RESULTS}

\section{Characteristics of participants}

A total of 459 patients were invited to participate. Of these, $57 \%$ (262 of 459) identified as female. The average age of invitees was 40.6 years (SD 16.1). Of those invited, 254 eligible patients participated in the survey, corresponding to a $55 \%$ (254 of 459) response rate. Of the participants, $56 \%$ (144 of 254) identified as female. The average age of the participants was 39.3 years (SD 15.7) and the median age was 37 years, ranging from 18 to 81 years old. The majority of participants had not had any symptoms of COVID-19 during the 3 months prior to the survey (218 of 254; 86\%). Only 17\% (44 of 254) of participants reported having had conducted a COVID-19 test, but only $9 \%$ (4 of 44) of those received a positive result. However, 6\% (16 of 254) reported that they presumed they had COVID-19 due to the presence of symptoms, despite not having taken a test. Quarantine was reported by $11 \%$ (28 of 254) of respondents. The PHQ results indicated that $17 \%$ (45 of 254) of patients suffered from impaired mental health, 6\% (17 of 254) suffered from depression, $4 \%$ (11 of 254) suffered from anxiety disorder, and 6\% (17 of 254) suffered from both depression and anxiety disorder.

\section{Impact of the pandemic on health}

One-third of respondents, $30 \%$ (75 of 254), indicated that their healthcare was affected by the COVID-19 pandemic (table 1). When asked to specify how their healthcare had been affected, respondents offered examples in the open-ended questions, including changes in appointment availability at their doctor's offices due to closures or modifications due to the pandemic (table 2; qualitative data with exemplary quotes are included in the online supplemental appendix 3).

One participant noted that 'Normal doctor's visits were no longer possible in the initial period. All appointments were canceled by the doctors. Only emergencies were possible.' Another described unexpected interruptions in care: 'After an operation I was in inpatient rehabilitation. This was planned for 3 weeks. However, after twoweeks the [name redacted] clinic was closed to be available for Corona patients.' A few participants noted issues in receiving necessary medications or necessary medical supplies, including for chronic conditions such as diabetes. Some indicated that they had felt increased stress and anxiety, such as one person who wrote that 'One reacts more sensitively to little things that used to be ignored (sneezing, coughing, etc).' Others experienced other changes in their mental health: 'During the lockdown, sleep disturbances, increased restlessness, fears about the future.' Moreover, difficult situations were made more difficult: 'In addition, I am currently unemployed and it is even more difficult for me to find a job, since I have to wear the mask for hours on end practically everywhere during work. My psyche suffers from it. I get scared and sometimes panic, as I am now worried about my health and professional life.'

During the COVID-19 pandemic, some respondents said they had health complaints, unrelated to COVID-19, for which they normally would have gone to see a doctor. The complaints included in the qualitative responses indicated covered a wide range of health problems, from relatively minor issues such as allergies or congestion to more serious conditions such as a slipped disc or a spinal canal stenosis. In the open-ended answers, respondents indicated that their concerns related to going to the doctor during the pandemic dealt with fear of contracting COVID-19, while a few individuals indicated that they felt their concerns were not substantial enough to see their doctor given that medical professionals were dealing with more serious health concerns during the pandemic. Many participants answered with variations on concerns that, 'I could catch it from the next patient in the office.' Others cited 'Risk of infection due to my age and certain preexisting conditions,' or doubted 'Whether my symptoms

Table 1 Impact of the pandemic on health, quantitative data

\begin{tabular}{lll}
\hline Question & Yes & No \\
\hline $\begin{array}{l}\text { Did you experience any health complaints during the COVID-19 pandemic (unrelated } \\
\text { to the coronavirus) for which you would normally go to the doctor? }\end{array}$ & $73 / 254(29 \%)$ & $181 / 254(71 \%)$ \\
$\begin{array}{l}\text { Was your healthcare affected by the COVID-19 pandemic, such as because a } \\
\text { doctor's office was closed, appointments were rescheduled, or for other reasons? }\end{array}$ & $75 / 254(30 \%)$ & $179 / 254(70 \%)$ \\
$\begin{array}{l}\text { At the beginning of the pandemic, several changes were made in healthcare delivery } \\
\text { to respond to the new needs created by the COVID-19 outbreak. Many physician } \\
\text { visits were postponed, office hours were curtailed, scheduled surgeries were }\end{array}$ & $63 / 254(25 \%)$ \\
$\begin{array}{l}\text { postponed to a later date, etc. Do you feel that you were affected by this? } \\
\text { Do you have any fears with regard to your future healthcare? }\end{array}$ & $601 / 254(75 \%)$ \\
\hline
\end{tabular}


Table 2 Impact of pandemic on health, summary of qualitative data

\begin{tabular}{|c|c|}
\hline Category & Code \\
\hline \multicolumn{2}{|c|}{ How health was affected by COVID-19 } \\
\hline \multirow[t]{2}{*}{ Due to COVID } & Symptoms of COVID \\
\hline & Self or relative tested positive \\
\hline \multirow[t]{3}{*}{ Due to change in care } & Appointments cancelled \\
\hline & Hard to get necessary supplies \\
\hline & Personal concern about going to doctor \\
\hline \multirow{5}{*}{$\begin{array}{l}\text { Changes in health due to } \\
\text { increased anxiety, fear, } \\
\text { stress }\end{array}$} & Depression \\
\hline & Concern that one might have COVID-19 \\
\hline & Isolation \\
\hline & Worsening of life circumstances \\
\hline & Stress \\
\hline \multirow{4}{*}{$\begin{array}{l}\text { Changes to work/home } \\
\text { routines }\end{array}$} & Home office \\
\hline & More work \\
\hline & Less work \\
\hline & Homeschooling/childcare \\
\hline \multirow{4}{*}{$\begin{array}{l}\text { Changes in free } \\
\text { time activities with a } \\
\text { connection to health }\end{array}$} & Specific activities not possible \\
\hline & $\begin{array}{l}\text { Loss of social contact in relation to change in } \\
\text { activities }\end{array}$ \\
\hline & $\begin{array}{l}\text { Physical problems in relation to change in } \\
\text { activities }\end{array}$ \\
\hline & Time for activities changed \\
\hline \multirow{2}{*}{$\begin{array}{l}\text { Changes in relation to } \\
\text { COVID-19 guidelines }\end{array}$} & Difficulty with specific precautions \\
\hline & Changes due to increased precautions \\
\hline \multirow[t]{6}{*}{ Changes in health } & Weight gain \\
\hline & Sleep changes \\
\hline & Less physical activity \\
\hline & New patterns of food/drink consumption \\
\hline & Mental health changes \\
\hline & Improvements \\
\hline \multirow[t]{3}{*}{ Not affected/no changes } & Healthy \\
\hline & No risks/low risk \\
\hline & Carefully following preventative measures \\
\hline
\end{tabular}

\section{Effects of quarantine}

$\begin{array}{ll}\text { No problems } & \text { Easy or necessary } \\ & \text { Made one appreciate non-quarantine time more } \\ & \text { Enjoyable } \\ \text { Mental health problems } & \text { Isolation } \\ & \text { Depression } \\ & \text { Stress } \\ \text { Health problems experienced during the pandemic for which one would } \\ \text { normally go to the doctor }\end{array}$

\section{Table 2 Continued}

Category Code

Mental or socioemotional Sleep problems

health

Depression

Treatment forgone Suspended or cancelled by medical office

Suspended or cancelled by patient

Self-treatment

\section{Concerns about going to the doctor during the pandemic}

Contagion concerns Catching COVID-19

Getting others sick with COVID-19

Quarantine

$\begin{array}{ll}\begin{array}{l}\text { Additional hassle during } \\ \text { pandemic }\end{array} & \text { Wait times } \\ & \text { Uncertainty } \\ \text { New COVID-19 rules } \\ \text { Burden for doctors }\end{array}$

None

No concerns

Effects of COVID-19 pandemic on healthcare

Difficulty getting care Closed medical offices

Scheduling difficulties

Appointments moved/cancelled

Only virtual or phone care

Materials availability Medication not available

issues

Medical office concerns Turned away due to COVID-19 concerns

Biggest challenges relating to health during the pandemic

Healthcare concerns Knowing when to get tested/care

In relation to care for children

In relation to care for self

Getting medications or healthcare supplies

\section{Concern related to Personal risk}

COVID-19 virus

Fear of contagion

Anxiety

Remaining healthy

COVID-19 guidelines Keeping distance

Mask wearing

Information

Quarantine

None None

Things that would make self-care easier during the pandemic

\begin{tabular}{ll} 
Nothing & None \\
Changes in relation to & Rural/urban \\
home life & Services \\
& Personal relationships \\
& Habits \\
Medical system changes & COVID-19 testing \\
& Remote care \\
& Scheduling \\
& Information \\
In relation to employer & Work load \\
\hline
\end{tabular}

Continued

Continued 


\begin{tabular}{ll}
\hline Table 2 Continued \\
\hline Category & Code \\
\hline Public life & Delivery services \\
& $\begin{array}{l}\text { Material needs } \\
\text { Changes in restrictions in relation to COVID-19 } \\
\text { Compliance with COVID-19 restrictions by others }\end{array}$ \\
\hline Personal impact of changes to healthcare delivery due to pandemic \\
\hline Medical system changes & $\begin{array}{l}\text { Appointments cancelled } \\
\text { Waiting time }\end{array}$ \\
& $\begin{array}{l}\text { Medical services redirected for COVID-19 care } \\
\text { Difficulty getting care }\end{array}$ \\
\hline Concerns with regard to healthcare provision in the future & Mental health \\
Health-concerns & $\begin{array}{l}\text { Physical health } \\
\text { Personal risk }\end{array}$ \\
Mental health \\
Physical health \\
Pealth-no concerns
\end{tabular}

were 'bad enough' to see a doctor.' A majority, or $70 \%$ (179 of 254) of respondents said that they had not been affected by the changes made to the healthcare system to respond to the needs created by the pandemic, such as postponed doctors' visits, restricted hours or healthcare services.

\section{Digital self-care practices in the pandemic}

More than one-third of respondents (38\%; 97 of 254), indicated that prior to the pandemic they engaged in practices to promote and maintain their health, such as the use of health apps, participation in online support groups or sports exercises, meditation or other activities for relaxation (table 3 ).

When asked to specify what kinds of practices, the majority of respondents cited exercise such as different sports, yoga or membership in fitness studios. During the pandemic, $39 \%$ of respondents indicated that they had initiated new or additional practices to improve their health. Sixteen per cent (41 of 254) were previously engaged in self-care activities, 23\% (59 of 254) of patients started new steps for the first time. The practices listed by respondents included a range of activities, many of which were not digital, such as yoga, healthier eating or new forms of physical activity (table 4). Some
Table 3 Impact of pandemic on digital self-care practices, quantitative data

\begin{tabular}{|c|c|c|}
\hline Question & Yes & No \\
\hline $\begin{array}{l}\text { Before the pandemic, did } \\
\text { you engage in any self-care } \\
\text { measures to maintain your } \\
\text { health, such as use of health } \\
\text { apps, participation in online } \\
\text { support groups, or exercise, } \\
\text { meditation, or other activities } \\
\text { for relaxation? }\end{array}$ & $\begin{array}{l}97 / 254 \\
(38 \%)\end{array}$ & $\begin{array}{l}157 / 254 \\
(62 \%)\end{array}$ \\
\hline $\begin{array}{l}\text { During/since the pandemic, } \\
\text { have you started new or } \\
\text { additional steps to improve } \\
\text { your health? }\end{array}$ & $\begin{array}{l}100 / 254 \\
(39 \%)\end{array}$ & $\begin{array}{l}154 / 254 \\
(61 \%)\end{array}$ \\
\hline $\begin{array}{l}\text { Since the pandemic, have } \\
\text { you sought more information } \\
\text { about your health? }\end{array}$ & $\begin{array}{l}27 / 254 \\
(11 \%)\end{array}$ & $\begin{array}{l}227 / 254 \\
(89 \%)\end{array}$ \\
\hline
\end{tabular}

noted the advantages of home office: 'Taking advantage of more flexible work schedule (virtual work) to eat more mindfully and reduce body weight by $\sim 2$ BMI points into the 25ish range.' Many described new fitness routines, such as 'Started jogging/walking more as an alternative to venturing out with friends to at least get out a bit,' or efforts to relax such as 'Self-massage of jaw muscles (watched online videos on how to do this), my friend now massages my neck and back more often, yoga exercises, exercises to strengthen arm, back and abdominal muscles, started jogging again, healthier diet, longer showers to relax.' However, only $11 \%$ (27 of 254) indicated that they had become more informed about their health since the start of the pandemic.

Respondents were asked what the greatest challenge was for them in relation to their health during the COVID-19 pandemic. The most common response in the qualitative data involved challenges in following the COVID-19 guidelines such as wearing masks or keeping social distance from family and friends, such as one participant who wrote: 'Keeping a distance, even from people you like very much!' Another described the difficulties of 'Dealing with everyday life with the social-distance regulations. Since not all people adhere to it, it makes shopping more difficult and also in professional life getting together with others.' Other challenges included not contracting COVID-19, heightened anxiety or concern over personal health risks, and concerns surrounding getting health needs met, for example, 'It's more of a psychological problem for me to have to deal with anxiety all the time because you don't know how badly the virus will hit you.' Some participants cited specific concerns with their own health: 'As a smoker with moderate obesity, I'm basically in the risk group,' and 'Since I'm 35 weeks pregnant, the impact on the pregnancy, the baby, the birth was one thing to deal with.'

About one-quarter, or 24\% (60 of 254) of individuals had fears with regard to their healthcare in the future. 
Table 4 Impact of pandemic on digital self-care practices, summary of qualitative data

\begin{tabular}{|c|c|}
\hline Category & Code \\
\hline \multicolumn{2}{|c|}{$\begin{array}{l}\text { Use of medical self-care measures to maintain health prior to the } \\
\text { pandemic }\end{array}$} \\
\hline \multirow[t]{4}{*}{ Sport } & Fitness studio courses \\
\hline & Group sports \\
\hline & Walking/jogging \\
\hline & Biking \\
\hline \multirow[t]{2}{*}{ Relaxation } & Meditation \\
\hline & Yoga \\
\hline \multirow[t]{2}{*}{ Nutrition } & Eating well \\
\hline & Supplements \\
\hline \multirow[t]{2}{*}{ Getting outside } & Garden work \\
\hline & Fresh air \\
\hline \multirow[t]{2}{*}{ Treatment with professionals } & Alternative treatments \\
\hline & Standard treatments \\
\hline \multicolumn{2}{|c|}{$\begin{array}{l}\text { Use of new or additional measures to maintain health during or } \\
\text { since the pandemic; if none, why not? }\end{array}$} \\
\hline Behaviour changes & Smoking \\
\hline \multirow[t]{4}{*}{ Activity changes } & Jogging/walking \\
\hline & Fitness studio activities \\
\hline & Biking \\
\hline & Online digital options \\
\hline \multirow[t]{2}{*}{ Nutrition } & Eating well \\
\hline & Supplements \\
\hline \multirow[t]{3}{*}{ Relaxation } & Meditation \\
\hline & Massage \\
\hline & Yoga \\
\hline Treatment with professionals & Standard treatments \\
\hline Outside & Fresh air \\
\hline \multirow{5}{*}{$\begin{array}{l}\text { Changes in relation to } \\
\text { COVID-19 guidelines }\end{array}$} & Social distancing \\
\hline & Hygiene \\
\hline & Staying home \\
\hline & Mask use \\
\hline & COVID-Warn app \\
\hline \multirow[t]{4}{*}{ None } & Not necessary \\
\hline & No risk \\
\hline & Same as before \\
\hline & No interest \\
\hline \multicolumn{2}{|c|}{ Motivations for seeking out health information } \\
\hline Increased concern & Fear \\
\hline \multirow[t]{3}{*}{ Prevention } & Personal precaution \\
\hline & Occupational precaution \\
\hline & Precaution for others \\
\hline \multirow[t]{2}{*}{ To be better informed } & In relation to COVID-19 risk \\
\hline & In relation to personal health knowledge \\
\hline
\end{tabular}

The open-ended answers to this question were particularly instructive, with a majority of respondents indicating that they were not concerned because they had faith in the German healthcare system, with participants noting that 'Even during the pandemic, I think [the healthcare system] worked much better in Germany than in many other countries around the world,' or 'Germany has a very stable and good healthcare system, so I don't see any reason to worry about it.' Others noted that their personal connection to their doctors helped to mitigate their concerns, for example, 'I trust my doctor and the system,' or 'Because I have a good general practitioner and everything is actually almost back to normal.' Approximately a quarter of respondents stated directly that they were not concerned for the future, with many citing their own fitness or lack of risk factors as the reason for their confidence.

\section{Associations with depression and anxiety disorder}

Patients with depression or anxiety disorder showed more adverse estimation of their healthcare situation (table 5). There was a strong association with previous COVID-19 infection and depression in the regression analysis (OR 21.41; $95 \%$ CI 1.98 to 231.12). The association between anxiety disorder and previous COVID-19 infection was not significant. Additionally, the multivariable logistic regression analysis revealed a strong association between previous quarantine and depression (OR 5.38; 95\% CI 2.20 to 13.17). The association with anxiety disorder was borderline significant (OR 2.78; 95\% CI 1.00 to 7.74). Survey responses regarding self-care practices were not significantly associated with depression or anxiety.

\section{DISCUSSION}

The self-estimation of the impact of the pandemic on their health showed that health was affected for many patients in only relatively minor ways. However, the provision of healthcare was affected for a greater number of people. The open-ended responses indicated that some people had significant health concerns, unrelated to COVID-19, for which they were unable to receive the necessary treatment, for example, medications that were undeliverable, or not receiving treatment for a slipped disc. The health of this group of individuals was considerably affected by the pandemic. We found no increased depression and anxiety rates. However, the risk of depression was significantly increased in patients with quarantine experience.

Self-care practices have increased during the pandemic, with a relevant number of people reporting the initiation of new activities. More than one-third (39\%) of participants indicated that they had started a new or additional self-care practice during the pandemic, such as yoga, meditation, exercise outdoors or a newfound emphasis on healthy eating habits, with $59(23 \%)$ patients who were not previously engaged in self-care practices starting new self-care activities for the first time. That said, while self-care is on the rise, there is no indication that digital self-care practices have taken on a major role during the pandemic in Germany, nor that digital self-care practices are being used in order to directly address problems associated with the pandemic. 
Table 5 Association of anxiety, depression and self-rated healthcare, adjusted for age and gender (only significant associations are presented)

\begin{tabular}{lllr}
\hline & OR & 95\% Cl & P value \\
\hline Logistic regression for depression & & & 0.012 \\
\hline COVID-19 positive & 21.41 & 1.98 to 231.12 & $<0.001$ \\
\hline Quarantine & 5.38 & 2.20 to 13.17 & $<0.001$ \\
\hline No COVID-19 symptoms & 0.20 & 0.09 to 0.45 & 0.001 \\
\hline Feeling affected by various healthcare changes & 4.33 & 1.88 to 9.99 & 0.014 \\
\hline Healthcare worsened & 3.56 & 1.29 to 9.86 & 0.038 \\
\hline COVID-19 negative & 2.46 & 1.05 to 5.75 & 0.318 \\
\hline Logistic regression for anxiety disorder & & 0.32 to 33.16 & 0.050 \\
\hline COVID-19 positive & 3.26 & 1.00 to 7.74 & $<0.001$ \\
\hline $\begin{array}{l}\text { Quarantine } \\
\text { Health complaints during COVID-19 pandemic for which }\end{array}$ participant would normally go to the doctor & 2.78 & 1.92 to 10.04 & $<0.001$ \\
\hline $\begin{array}{l}\text { Feeling affected by various healthcare changes } \\
\text { Healthcare worsened }\end{array}$ & 4.39 & 2.52 to 14.09 & 0.001 \\
\hline $\begin{array}{l}\text { Healthcare not changed } \\
\text { Healthcare affected by COVID-19 pandemic because of doctor's }\end{array}$ & 3.52 & 1.97 to 13.01 & 0.002 \\
\hline offices closures, cancelled appointments & 5.95 & 0.10 to 0.59 & 0.002 \\
\hline I cannot assess changes in healthcare delivery & 5.06 & 1.56 to 7.95 & 0.040 \\
\hline \begin{tabular}{l} 
Fears with regard to future healthcare delivery \\
\hline
\end{tabular} & 2.35 & 1.04 to 5.31 & 0.049 \\
\hline
\end{tabular}

The pandemic has affected different socioeconomic groups in Germany unequally. ${ }^{38}$ Given that most digital self-care practices must be paid for out-of-pocket, it is possible that engagement with digital self-care may be stratified along socioeconomic lines. Further, it is possible that digital self-care fills a 'gap' in healthcare provision that may be more appealing for patients in places where basic healthcare needs are not met through universal health insurance. In places like Germany where the healthcare system is based on solidarity and basic needs are, on the whole, met for the majority of the population, ${ }^{39}$ it is possible that there is less need or incentive to seek out digital self-care practices. Future research on digital self-care in Germany and also internationally can address how changes in self-care practices are related to forms of social and health inequality, and the intersections between major public health events and the need for new or different forms of care that are not available through the standard provision.

The increase in new self-care practices to improve health was not accompanied by an increase in informationseeking about health. A study in Germany found that access to health information could serve as a buffer for increased anxiety during the pandemic, ${ }^{40}$ while another study found that nearly half of participants had difficulty judging if information about the pandemic was accurate or trustworthy. ${ }^{41}$ Thus, the relationship between information and anxiety during public health crises remains disputed, ${ }^{42} 43$ and further study is needed to probe the effects of the lack of reported health information-seeking behaviour during the pandemic.

An unintended finding affirmed in this survey is that there is great confidence in German healthcare system to adapt to changes brought about by the pandemic and address health needs accordingly. This correlates with findings that $85 \%$ of individuals surveyed in Germany were optimistic about their future access to healthcare services. ${ }^{44}$ Given that in many cases self-care is taken up to gain a sense of control over one's health, or because a particular health service is not available, is possible that widespread faith in the healthcare system leads to lower levels of digital self-care practice. When patient's needs are, on the whole, met by the healthcare system, there may be lower levels of digital self-care seeking behaviour.

The prevalence of depression and anxiety in our primary care collective was very similar to a previous survey in the same region in $2010 .^{45}$ Therefore, our findings contradict the results from a survey conducted across Germany which found significantly increased symptoms of anxiety, depression, psychological distress and COVID19-related fear. ${ }^{46}$ Their online survey was performed in the beginning of the pandemic, from March to May 2020. The summer period was significantly calmer with regard to the pandemic in Germany and Europe, which might explain the decreased prevalence of depression and anxiety in our study. However, our study indicates that there is a relatively small but very vulnerable patient group requiring special attention and services. There 
was a strong relationship between previous COVID-19 infection and quarantine experience and increased depression. Beyond that, the qualitative analysis suggests important health concerns of many patients which might be difficult to capture with psychometric questionnaires. Therefore, general practitioners should be aware that many patients experience a psychological crisis due to the isolation.

\section{Limitations}

A limitation of the study is the response rate of $55.3 \%$. However, there was no conspicuous difference between the consecutively invited patient sample and the responders. The proportion of patients with depression, anxiety and COVID-19 infection, respectively, was comparatively low, which explains the breadth of the $95 \%$ CIs. However, the ORs were rather high. Only patients with internet skills could participate. Many patients answered the open-ended questions with relatively short phrases or words, and given the survey format it is not possible to probe for further clarification. No socioeconomic information was recorded. Patients were interviewed before the second lockdown which lasted considerably longer than the lockdown during the 'first wave'. It is thus to be expected that patients suffered from more psychological constraints after the second long-term lockdown period. Finally, due to time constraints and challenges of coordinating a new study while all researchers were working from home during the pandemic, there was no patient involvement in the survey design or data interpretation.

\section{CONCLUSIONS}

Healthcare was affected for participants during the pandemic. There was a marked increase in self-care practices during the pandemic to promote and maintain health; however, these do not appear to be predominantly digital in nature. Given that important differences have already been seen between digital self-care practices in the literature and in Germany, ${ }^{13}$ further research on selfdirected health promotion during the pandemic will help to illuminate how these findings from Germany compare with other locales. Our findings show that patients with quarantine experience suffer significantly more from anxiety and depression. Further research is necessary to develop strategies to help alleviate the burden of the quarantine experience, which can be particularly challenging for patients. Whether or not digital self-care tools could also be a means of alleviating some of the additional stress and isolation posed by a quarantine during a public health event can be further investigated.

Acknowledgements The authors would like to thank the general practitioners and their practice assistants for their help inviting participants to complete the survey.

Contributors $A F, A B$ and $A S$ conceived of the study and designed the survey. AS was responsible for study coordination with the general practice offices. AS and SK completed the statistical analysis of the quantitative data and contributed relevant summaries for the article. AF completed the qualitative analysis of the data and was responsible for the analysing the quantitative results together with the qualitative data. AF drafted the paper with assistance and feedback of SM and AB. AS helped with writing. All authors reviewed and approved the final version of this article.

Funding This work was supported by the Institute of History and Ethics in Medicine and the Institute of General Practice and Health Services Research, both of the TUM School of Medicine.

Competing interests None declared.

Patient consent for publication Not required.

Ethics approval This study was approved by the Technical University of Munich's Research Ethics Committee on 19 May 2020 (311/20 S). All participants gave consent to proceed before initiating the survey.

Provenance and peer review Not commissioned; externally peer reviewed.

Data availability statement The quantitative dataset generated and analyzed during the current study are available from the corresponding author on reasonable request. Due to privacy concerns, the qualitative data cannot be made publicly available.

Supplemental material This content has been supplied by the author(s). It has not been vetted by BMJ Publishing Group Limited (BMJ) and may not have been peer-reviewed. Any opinions or recommendations discussed are solely those of the author(s) and are not endorsed by BMJ. BMJ disclaims all liability and responsibility arising from any reliance placed on the content. Where the content includes any translated material, BMJ does not warrant the accuracy and reliability of the translations (including but not limited to local regulations, clinical guidelines, terminology, drug names and drug dosages), and is not responsible for any error and/or omissions arising from translation and adaptation or otherwise.

Open access This is an open access article distributed in accordance with the Creative Commons Attribution Non Commercial (CC BY-NC 4.0) license, which permits others to distribute, remix, adapt, build upon this work non-commercially, and license their derivative works on different terms, provided the original work is properly cited, appropriate credit is given, any changes made indicated, and the use is non-commercial. See: http://creativecommons.org/licenses/by-nc/4.0/.

\section{ORCID iDs}

Amelia Fiske http://orcid.org/0000-0001-7207-6897

Stuart McLennan http://orcid.org/0000-0002-2019-6253

\section{REFERENCES}

1 Die Bundesregierung. Besprechung der Bundeskanzlerin mit den Regierungschefinnen und Regierungschefs der Länder am 12, 2020. Available: https://www.bundesregierung.de/breg-de/themen/ coronavirus/beschluss-zu-corona-1730292

2 Ellyatt $\mathrm{H}$. "Collateral damage": Germany has limited its coronavirus death toll, but it hasn't escaped criticism. CNBC [Internet], 2020. Available: https://www.cnbc.com/2020/09/23/germany-has-limitedits-coronavirus-death-toll-but-faces-criticism.html

3 Moreno C, Wykes T, Galderisi S, et al. How mental health care should change as a consequence of the COVID-19 pandemic. Lancet Psychiatry 2020;7:813-24.

4 Rajkumar RP. COVID-19 and mental health: a review of the existing literature. Asian J Psychiatr 2020;52:102066.

5 Jung S, Kneer J, Kruger THC. The German COVID-19 survey on mental health: primary results. medRxiv 2020.

6 González-Sanguino C, Ausín B, Castellanos Miguel Ángel, et al. Mental health consequences during the initial stage of the 2020 coronavirus pandemic (COVID-19) in Spain. Brain Behav Immun 2020;87:172-6.

7 Peters A, Rospleszcz S, Greiser KH. The impact of the COVID-19 pandemic on self-reported health. Dtsch Ärztebl 2020;117:861-7.

8 Arendt F, Markiewitz A, Mestas M, et al. COVID-19 pandemic, government responses, and public mental health: investigating consequences through crisis Hotline calls in two countries. Soc Sci Med 2020;265:113532.

9 Schweda A, Weismüller B, Bäuerle A, et al. Phenotyping mental health: age, community size, and depression differently modulate COVID-19-related fear and generalized anxiety. Compr Psychiatry 2021;104:152218.

10 Liu S, Heinzel S, Haucke MN, et al. Increased psychological distress, loneliness, and unemployment in the spread of COVID-19 over 6 months in Germany. Medicina 2021;57. doi:10.3390/ medicina57010053. [Epub ahead of print: 09 Jan 2021].

11 Riedel-Heller S, Richter D. [COVID-19 Pandemic and Mental Health of the General Public: Is there a Tsunami of Mental Disorders?]. Psychiatr Prax 2020;47:452-6. 
12 Fullana MA, Hidalgo-Mazzei D, Vieta E, et al. Coping behaviors associated with decreased anxiety and depressive symptoms during the COVID-19 pandemic and lockdown. J Affect Disord 2020;275:80-1.

13 Fiske A, Buyx A, Prainsack B. The double-edged sword of digital self-care: physician perspectives from Northern Germany. Soc Sci Med 2020;260:113174.

14 Ruckenstein M, Schüll ND. The Datafication of health. Annu Rev Anthropol 2017;46:261-78.

15 Prainsack B. Personalized medicine: Empowered patients in the 21st century? New York: NYU Press, 2017: 288.

16 Topol E. The patient will see you now: the future of medicine is in your hands. Reprint edn. New York, NY: Basic Books, 2016: 384

17 Lupton $\mathrm{D}$. The digitally engaged patient: self-monitoring and selfcare in the digital health era. Soc Theory Health 2013;11:256-70.

18 World Health Organization. Health Education in Self-Care: Possibilities and Limitations [Internet], 1983. Available: http://apps. who.int/iris/bitstream/10665/70092/1/HED 84.1.pdf

19 Ming LC, Untong N, Aliudin NA, et al. Mobile health Apps on COVID-19 Launched in the early days of the pandemic: content analysis and review. JMIR Mhealth Uhealth 2020;8:e19796.

20 legroju. Digital health technologies addressing the pandemic [Internet]. Shaping Europe's digital future - European Commission, 2020. Available: https://ec.europa.eu/digital-single-market/en/digitalhealth-technologies-addressing-pandemic

21 Expert Self Care. Coronavirus Support App [Internet]. Available: https://www.expertselfcare.com/health-apps/coronavirus-supportapp-uk/

22 Finch S. 5 Mental Health Apps to Help Manage Coronavirus Anxiety [Internet]. Healthline, 2020. Available: https://www.healthline.com/ health/mental-health/5-mental-health-apps-to-help-managecoronavirus-anxiety

23 Wjst M. [The early phase of the COVID-19 pandemic in Bavaria, Germany]. Dtsch Med Wochenschr 2021;146:e1-9.

24 Zimmermann BM, Fiske A, Prainsack B, et al. Early perceptions of COVID-19 contact tracing Apps in German-Speaking countries: comparative mixed methods study. J Med Internet Res 2021;23:e25525.

25 Le Ker H. Hospitals in Germany Ready Themselves for the Worst. Der Spiegel [Internet], 2020. Available: https://www.spiegel.de/ international/germany/hospitals-in-germany-ready-themselves-forthe-worst-a-3fe76172-b3f4-4332-9261-561d049b151a

26 Fegert JM, Schulze UME. COVID-19 and its impact on child and adolescent psychiatry - a German and personal perspective. Ir J Psychol Med 2020;37:243-5.

27 Bayerisches Ministerialblatt. Bayerische Verordnung über Infektionsschutzmaßnahmen anlässlich der Corona-Pandemie (Bayerische Infektionsschutzmaßnahmenverordnung - BaylfSMV). BayMBI, 2020.

28 Gerke S, Stern AD, Minssen T. Germany's digital health reforms in the COVID-19 era: lessons and opportunities for other countries. NPJ Digit Med 2020;3:1-6

29 Rövekamp M. Hilfe bei Depressionen: "Es ist Wahnsinn, was gerade in Deutschland passiert”. Der Tagesspiegel [Internet], 2021. Available: https://plus.tagesspiegel.de/wirtschaft/hilfe-bei-depressionen-es-istwahnsinn-was-gerade-in-deutschland-passiert-92552.html

30 von Elm E, Altman DG, Egger M, et al. Strengthening the reporting of observational studies in epidemiology (STROBE) statement: guidelines for reporting observational studies. BMJ 2007;335:806-8.

31 O'Brien BC, Harris IB, Beckman TJ, et al. Standards for reporting qualitative research: a synthesis of recommendations. Acad Med 2014;89:1245-51.

32 Löwe B, Spitzer RL, Gräfe K, et al. Comparative validity of three screening questionnaires for DSM-IV depressive disorders and physicians' diagnoses. J Affect Disord 2004;78:131-40.

33 Löwe B, Decker O, Müller S, et al. Validation and standardization of the generalized anxiety disorder screener (GAD-7) in the general population. Med Care 2008;46:266-74.

34 Lupton D. Digital health: critical and cross-disciplinary perspectives. 1st edn. London: Taylor and Francis, 2017.

35 Topol E. Digital medicine: empowering both patients and clinicians. Lancet 2016;388:740-1.

36 Gabriels K, Moerenhout T. Exploring entertainment medicine and professionalization of self-care: interview study among doctors on the potential effects of digital Self-Tracking. J Med Internet Res 2018;20:e10.

37 Hsieh H-F, Shannon SE. Three approaches to qualitative content analysis. Qual Health Res 2005;15:1277-88.

38 Wachtler B, Hoebel J. [Social Inequalities and COVID-19: SocialEpidemiological Perspectives on the Pandemic]. Gesundheitswesen Bundesverb Arzte Offentlichen Gesundheitsdienstes Ger 2020;82:670-5.

39 Institute for Quality and Efficiency in Health Care. Health care in Germany: The German health care system [Internet]. InformedHealth. org [Internet]. Cologne, Germany: Institute for Quality and Efficiency in Health Care (IQWiG), 2015. http://www.ncbi.nlm.nih.gov/books/ NBK298834/

40 Jungmann SM, Witthöft M. Health anxiety, cyberchondria, and coping in the current COVID-19 pandemic: which factors are related to coronavirus anxiety? J Anxiety Disord 2020;73:102239.

41 Okan O, Bollweg TM, Berens E-M, et al. Coronavirus-Related health literacy: a cross-sectional study in adults during the COVID-19 Infodemic in Germany. Int J Environ Res Public Health 2020;17. doi:10.3390/ijerph17155503. [Epub ahead of print: 30 Jul 2020]

42 Garfin DR, Silver RC, Holman EA. The novel coronavirus (COVID-2019) outbreak: amplification of public health consequences by media exposure. Health Psychol 2020;39:355-7.

43 Gao J, Zheng P, Jia Y, et al. Mental health problems and social media exposure during COVID-19 outbreak. PLoS One 2020;15:e0231924.

44 Hajek A, De Bock F, Wieler LH, et al. Perceptions of health care use in Germany during the COVID-19 pandemic. Int J Environ Res Public Health 2020;17:9351.

45 Schneider A, Wartner E, Schumann I, et al. The impact of psychosomatic co-morbidity on discordance with respect to reasons for encounter in general practice. J Psychosom Res 2013;74:82-5.

46 Bäuerle A, Teufel M, Musche V, et al. Increased generalized anxiety, depression and distress during the COVID-19 pandemic: a crosssectional study in Germany. J Public Health 2020;42:672-8. 